\title{
Temporally Dependent Changes in Cocaine-Induced Synaptic Plasticity in the Nucleus Accumbens Shell are Reversed by DI-Like Dopamine Receptor Stimulation
}

\author{
Pavel I Ortinski*,', Fair M Vassoler', Gregory C Carlson' and R Christopher Pierce' \\ 'Department of Psychiatry, Center for Neurobiology and Behavior, Perelman School of Medicine at the University of Pennsylvania, Philadelphia, \\ PA, USA
}

\begin{abstract}
Dopaminergic and glutamatergic inputs to the nucleus accumbens shell have a central role in reward processing. Non-contingent cocaine administration generates a number of long-term AMPA receptor-dependent changes in synaptic efficacy. However, the synaptic consequences of cocaine self-administration and the potential role of dopamine in these processes remain unclear. Here, we examined the influence of DI dopamine receptor (DIDR) activation on excitatory synaptic plasticity in the accumbens shell of adult rats following cocaine self-administration. Our results indicated that during the first 2 days following cocaine exposure both pre- and post-synaptic mechanisms contribute to a net decrease in AMPA receptor-mediated signaling. This is reflected by decreased frequency of miniature EPSCs (mEPSCs) attributable to enhanced cannabinoid receptor activity, decreased mEPSC amplitude, and increased paired-pulse ratio of evoked EPSCs. In contrast, the only changes observed in the shell 3-4 weeks following cocaine self-administration were increased mEPSCs amplitudes and AMPA/NMDA ratios. We further found that although these cocaine-induced neuroadaptations during early and late abstinence have different synaptic expression mechanisms, they were normalized by stimulation of DIDRs. Thus, pre-exposure to the DIDR agonist, SKF38393, during the initial period of abstinence increased excitatory synaptic strength, but reduced excitatory signaling after weeks of abstinence. Taken together, these results indicate that the direction of changes in excitatory transmission induced by cocaine self-administration switches over the first few weeks of abstinence. Moreover, DIDRs gate the stability of these cocaineinduced changes at glutamatergic synapses in the accumbens shell by utilizing multiple temporally distinct mechanisms, which has implications for the treatment of cocaine craving and addiction.

Neuropsychopharmacology (2012) 37, I67I-1682; doi:I0.I038/npp.2012.12; published online I4 March 2012
\end{abstract}

Keywords: cocaine; self-administration; electrophysiology; AMPA; synaptic plasticity

\section{INTRODUCTION}

Repeated exposure to cocaine results in changes in glutamatergic AMPA receptor-mediated neurotransmission in the nucleus accumbens shell that may contribute to cocaine craving and relapse (Kalivas and O'Brien, 2008; Schmidt and Pierce, 2010; Wolf, 2010). The changes in AMPA-mediated synaptic transmission are sensitive to the duration of abstinence from cocaine administration. Thus, during the first few days of abstinence following repeated non-contingent cocaine administration the ratio of AMPA to NMDA receptor-mediated currents as well as the intrinsic

*Correspondence: Dr PI Ortinski, Department of Psychiatry, Center for Neurobiology and Behavior, Perelman School of Medicine at the University of Pennsylvania, TRL Suite 1110, 125 S 31st Street, Philadelphia, PA 19104, USA, Tel: + I 215573 5202, Fax: + 1215 573 7605, E-mail: ortinski@mail.med.upenn.edu

Received 2 August 201 I; revised 10 January 2012; accepted 23 January 2012 excitability of the accumbens shell medium spiny neurons (MSNs) are decreased (Kourrich et al, 2007; Kourrich and Thomas, 2009, but see Dobi et al, 2011; Kim et al, 2011). At longer abstinence periods ( $>10$ days) the AMPA/NMDA ratio in the shell increases (Kourrich et al, 2007) as does the amplitude and frequency of AMPA-mediated miniature EPSCs (mEPSCs) (Kourrich et al, 2007; Thomas et al, 2001; Dobi et al, 2011). Consistent with these results, the cocaineinduced synaptic changes at excitatory synapses in the shell are accompanied by changes in the expression of specific AMPA receptor subunits. Surface expression of GluA1, GluA2, and GluA2/A3 subunits of the AMPA receptor at early abstinence in the nucleus accumbens decreases (Schumann and Yaka, 2009) or remains unchanged (Boudreau and Wolf, 2005; Boudreau et al, 2009; Ghasemzadeh et al, 2009), but increases following more prolonged abstinence from experimenteradministered cocaine (Boudreau and Wolf, 2005; Boudreau et al, 2007, 2009; Ghasemzadeh et al, 2009; Schumann and Yaka, 2009; Ferrario et al, 2010). 
Although ample evidence suggests that neuroadaptations in the nucleus accumbens are sensitive to the mode of cocaine intake (Crespo et al, 2002; Mu et al, 2010; McCutcheon et al, 2011; Kalivas and McFarland, 2003; Bowers et al, 2010), a systematic analysis of excitatory synaptic function following self-administered cocaine is lacking. In the nucleus accumbens shell, one study reported reduced excitation during early abstinence from cocaine self-administration using extracellular field potential recordings (SchrammSapyta et al, 2006). More evidence is available with regard to specific contribution of calcium-permeable, GluA2-lacking AMPA receptors after abstinence from self-administration, although the results vary (Conrad et al, 2008; Mameli et al, 2009; McCutcheon et al, 2011). In biochemical studies, cocaine self-administration decreases the surface expression of GluA1 subunits in the nucleus accumbens 1 day after the cessation of cocaine treatment but increases surface GluA1 and GluA1-pSer845 after extended forced abstinence (Conrad et al, 2008; Ferrario et al, 2011). Overall, it remains unclear to what extent the synaptic plasticity observed following experimenter-administered cocaine is preserved when cocaine intake is voluntary.

Many of cocaine's characteristic behavioral and neuronal effects result from increases in extracellular dopamine and the subsequent stimulation of D1 dopamine receptors (D1DRs) (Pierce and Kumaresan, 2006). Notably, stimulation of D1DRs in the nucleus accumbens shell facilitates reinstatement of cocaine seeking (Schmidt et al, 2006). In terms of synaptic strength, acute application of D1DR agonists suppresses AMPA receptor-mediated currents via a pre-synaptic mechanism (Pennartz et al, 1992; Nicola et al, 1996; Harvey and Lacey, 1996). Agonist-induced activation of D1DRs, however, has also been shown to increase the surface expression of AMPA receptors in a PKA-dependent manner (Chao et al, 2002; Mangiavacchi and Wolf, 2004), an effect that was potentiated following cocaine self-administration (Anderson et al, 2008). D1DR activation may elicit lasting synaptic effects that persist beyond the duration of the agonist application (Schilström et al, 2006). Such lasting effects are of particular relevance with regard to cocaineinduced relapse. Even after prolonged periods of abstinence in human cocaine users, a single exposure to cocaine may elicit an extended period of relapse to cocaine taking, an effect that is presumably driven by enduring cocainetriggered neuroadaptations in the relevant brain circuits. In this study, we used a conventional regimen of cocaine self-administration to examine AMPA-mediated neuronal transmission and to determine the lasting influence of D1DR stimulation on cocaine-induced synaptic plasticity in the nucleus accumbens shell of adult rats following brief and extended abstinence.

\section{SUBJECTS AND METHODS}

\section{Animals}

Male Sprague-Dawley rats (Rattus norvegicus) weighing 300-350 g were obtained from Taconic Laboratories (Germantown, NY). Animals were individually housed, with food and water available ad libitum in the home cage. A 12-12-h light-dark cycle was used with the lights on at 0700 hours. All behavioral training was performed during the light cycle. All experimental protocols were approved by the Institutional Animal Care and Use Committee of the University of Pennsylvania.

\section{Surgery and Self-Administration Training}

Before surgery, the rats were anesthetized with injections of $80 \mathrm{mg} / \mathrm{kg}$ ketamine (i.p.) and $12 \mathrm{mg} / \mathrm{kg}$ xylazine (i.p.). An indwelling catheter (Strategic Applications) was placed into the right jugular vein and sutured in place. The catheter was routed subcutaneously to a mesh platform placed and sutured between the shoulder blades. Catheters were flushed daily with $0.3 \mathrm{ml}$ of the antibiotic Timentin $(0.93 \mathrm{mg} / \mathrm{ml})$ dissolved in heparinized saline. The catheters were sealed with plastic obturators when not in use. After a 7-day recovery period from surgery, the rats were placed in operant chambers (Med Associates) and allowed to leverpress for intravenous cocaine infusions $(0.25 \mathrm{mg}$ cocaine per $56 \mu$ saline over a $5 \mathrm{~s}$ infusion) during daily 2 -h selfadministration sessions. Each cocaine infusion was followed by a 20 -s timeout period during which responses had no scheduled consequences. The rats were initially trained using a fixed ratio 1 (FR1) schedule of reinforcement. When stable responding was achieved under the FR1 schedule, they were switched to an FR5 schedule. Rats self-administered cocaine for 14 days and were paired with yoked saline controls. The yoked animals received an infusion of saline every time its pair received cocaine. There were no consequences to lever pressing by the yoked saline animals.

A subset of rats was implanted with bilateral guide cannulae (14 mm 24-gauge tubing; Small Parts) $2 \mathrm{~mm}$ dorsal to the nucleus accumbens shell for microinjection experiments. The stereotaxic coordinates, relative to bregma, were as follows: $1.0 \mathrm{~mm}$ anterior, $\pm 1.0 \mathrm{~mm}$ lateral, $5.0 \mathrm{~mm}$ ventral. Cannulae were cemented in place by affixing dental acrylic to three stainless steel screws fastened to the skull. In order to prevent occlusion of the guide cannulae, an obturator (14 mm, 33-gauge wire) was inserted into each one.

\section{Microinjections}

Obturators were removed from the guide cannulae and 33gauge stainless steel microinjectors (Small Parts) were inserted. These microinjectors were cut to a length that extended $2 \mathrm{~mm}$ below the ventral end of the guide cannulae and into the shell of the nucleus accumbens. Bilateral infusions were performed simultaneously over a 120 -s time period in a total volume of $0.5 \mu \mathrm{l}$ per side. Following the microinjections, guide cannulae were left in place for $60 \mathrm{~s}$ in order to allow the solution to diffuse away from the tips of the cannulae before they were removed. The animals were killed 20-30 min following the microinjections and the brains processed for electrophysiological analyses. The correct placement of the guide cannulae was verified by the presence of the cannula track in the nucleus accumbens shell during electrophysiological recordings.

\section{Nucleus Accumbens Slices}

The rats were decapitated following isoflurane anesthesia 1-2 days (early abstinence) or 23-30 days (late abstinence) 
following 14 days of cocaine self-administration. The brain was removed and coronal slices $(300 \mu \mathrm{m})$ containing the nucleus accumbens were cut with a Vibratome (VT1000S, Leica Microsystems) in an ice-cold artificial cerebrospinal fluid solution (ACSF), in which $\mathrm{NaCl}$ was replaced by an equiosmolar concentration of sucrose. ACSF consisted of $130 \mathrm{mM} \mathrm{NaCl}, 3 \mathrm{mM} \mathrm{KCl}, 1.25 \mathrm{mM} \mathrm{NaH} \mathrm{PO}_{4}, 26 \mathrm{mM}$ $\mathrm{NaHCO}_{3}, 10 \mathrm{mM}$ glucose, $1 \mathrm{mM} \mathrm{MgCl} 2$, and $2 \mathrm{mM} \mathrm{CaCl}_{2}(\mathrm{pH}$ 7.2-7.4 when saturated with $95 \% \mathrm{O}_{2} / 5 \% \mathrm{CO}_{2}$ ). Slices were incubated in ACSF at $32-34{ }^{\circ} \mathrm{C}$ for $45 \mathrm{~min}$ and kept at $22-$ $25^{\circ} \mathrm{C}$ thereafter, until transfer to the recording chamber. A subset of slices from each animal was incubated with ACSF supplemented with SKF38393 (10 $\mu$ M; Sigma) for 1-3 h. The partial SKF38393 was chosen on the bases of its pharmacological similarity to dopamine (Ryman-Rasmussen et al, 2005) and its ability to modulate excitability of the nucleus accumbens neurons with efficiency that matches or exceeds that of the full agonist SKF81297 (Johansen et al, 1991). Slices pre-exposed to SKF38393 were washed with regular ACSF for at least $10 \mathrm{~min}$ before initiation of the recordings. Importantly, we observed no correlation between the SKF38393 incubation and wash-out times and any of the measures reported in this study (median $r^{2}=0.03$ ). The osmolarity of all solutions was 305315 mOsm. Slices were viewed using infrared differential interference contrast optics under an upright microscope (Eclipse FN1, Nikon Instruments) with a $40 \times$ waterimmersion objective.

\section{Electrophysiology}

The recording chamber was continuously perfused (1-2 $\mathrm{ml} /$ min) with oxygenated ACSF heated to $32 \pm 1^{\circ} \mathrm{C}$ using an automatic temperature controller (Warner Instruments). Picrotoxin $(100 \mu \mathrm{M})$ was added to all solutions to block the $\mathrm{GABA}_{\mathrm{A}}$ receptor-mediated currents. For mEPSC experiments, tetrodotoxin $(1 \mu \mathrm{M})$ was present in the bath. Recording pipettes were pulled from borosilicate glass capillaries (World Precision Instruments) to a resistance of 4-7 M $\Omega$ when filled with the intracellular solution. The intracellular solution contained (in $\mathrm{mM}$ ): $100 \mathrm{CsCH}_{3} \mathrm{O}_{3} \mathrm{~S}, 50$ $\mathrm{CsCl}, 3 \mathrm{KCl}, 0.2$ BAPTA, 10 HEPES, $1 \mathrm{MgCl}_{2}, 2.5$ phosphocreatine-2Na, 2 Mg-ATP, 0.25 GTP-Tris, 5 QX-314, adjusted to $\mathrm{pH}$ 7.2-7.3 (pH 7.2-7.3 with $\mathrm{CsOH}$, osmolarity 280-290 mOsm). For some mEPSC recordings, the intracellular solution contained (in $\mathrm{mM}$ ): 145 potassium gluconate, $2 \mathrm{MgCl}_{2}, 2.5 \mathrm{KCl}, 2.5 \mathrm{NaCl}, 0.1$ BAPTA, 10 HEPES, $2 \mathrm{Mg}$ ATP, 0.5 GTP-Tris, and 5 QX-314 (pH 7.2-7.3 with KOH, osmolarity $280-290 \mathrm{mOsm}$ ). No differences in amplitude, frequency, or decay kinetics were observed between $\mathrm{K}$ gluconate and Cs-containing solutions and these data were pooled for analyses. Alexa $568(200 \mu \mathrm{M})$ was also included in the intracellular solution in some recordings. MSNs in the nucleus accumbens shell were identified by their morphology and the low resting membrane potential $(-70$ to $-85 \mathrm{mV}$ ). eEPSC and $\mathrm{mEPSC}$ recordings were conducted in whole-cell voltage-clamp mode $\left(V_{\mathrm{h}}=-70\right.$ and $+40 \mathrm{mV}$ for eEPSC and $V_{\mathrm{h}}=-70 \mathrm{mV}$ for mEPSCs). AM251 was applied via the Y-tube perfusion system (Murase et al, 1989) modified for optimal solution exchange in brain slices (Hevers and Lüddens, 2002). In experiments with AM251, mEPSCs were analyzed after a minimum of 3 min of AM251 application. All recordings were conducted with a MultiClamp700B amplifier (Molecular Devices). Currents were low-pass filtered at $2 \mathrm{kHz}$ and digitized at $20 \mathrm{kHz}$ using a Digidata $1440 \mathrm{~A}$ acquisition board and pClamp10 software (both from Molecular Devices). Access resistance (10-30 M $\Omega$ ) was monitored throughout the recordings by injection of $10 \mathrm{mV}$ hyperpolarizing pulses and data were discarded if access resistance changed by $>25 \%$ over the course of data acquisition. Evoked responses were triggered by $100 \mu \mathrm{s}$ constant-current pulses generated by an A310 Accupulser (World Precision Instruments) and delivered at $0.1 \mathrm{~Hz}$ via a bipolar tungsten stimulation electrode positioned within $100 \mu \mathrm{m}$ of the recorded cell. The amplitude of the current pulses was controlled by a stimulus isolator (ISO-Flex, AMPI) and was adjusted to elicit monosynaptic responses in the range of $100-300 \mathrm{pA}$ (the required stimulus intensity ranged from 15 to $80 \mu \mathrm{A})$.

\section{Data Analysis and Statistics}

All analyses of intracellular recordings were carried out with Clampfit 10 (Molecular Devices). The time constant of decay was based on a monoexponential fit to the decay phase of an average mEPSCs trace computed from a minimum of 50 individual mEPSCs. For the cumulative probability distribution plots, 100-150 individual mEPSCs were analyzed. Mean mEPSC frequencies were analyzed from 10- to 20 -s long trace segments. Paired-pulse ratios (PPRs) were calculated by averaging 5-10 responses at each stimulus interval and dividing the peak amplitude of the second eEPSC by the peak amplitude of the first eEPSC. AMPA/ NMDA current ratios were computed by dividing the mean peak eEPSC at $-70 \mathrm{mV}$ (AMPA-mediated) by the mean amplitude at $+40 \mathrm{mV}, 35 \mathrm{~ms}$ after the peak over a $2 \mathrm{~ms}$ window (NMDA-mediated). The mean eEPSCs were based on 50 individual responses at each holding potential.

Cells from 4 to 7 animals were analyzed in each experimental condition. The data were expressed as mean \pm SEM of cells per group (all figures) as well as the mean \pm SEM of recorded cells from a single animal that were then averaged across the group (see Table 1). These analyses produced identical statistical interpretation of the results. Statistical analyses were performed with Microsoft Excel or StatView 5.0.1 for Windows. Statistical comparisons were done using two-tailed unpaired Student's $t$-test, two-way ANOVA (with Tukey's HSD post hoc) or Kolmogorov-Smirnov (K-S) as appropriate.

\section{RESULTS}

\section{Temporally Dynamic Changes of mEPSCs are Regulated by D1DR Activation}

We began our study by examining the effect of cocaine selfadministration on a basic measure of synaptic signaling, mEPSCs, in the nucleus accumbens shell MSNs (Figure 1a). mEPSCs are quantal post-synaptic responses to spontaneous, action potential-independent release of neurotransmitter vesicles that can be isolated by application of a voltage-gated $\mathrm{Na}^{+}$channel blocker, tetrodotoxin $(1 \mu \mathrm{M})$. Following 1-2 days of forced cocaine abstinence, the basal mEPSC amplitude in cells from cocaine-experienced animals 
was $23 \%$ smaller than in cells from yoked saline controls (Figures $1 \mathrm{~b}$ and $\mathrm{c}$ ). To examine if mEPSCs were sensitive to D1DR stimulation, a subset of slices was incubated with D1DR agonist, SKF38393 (10 $\mu \mathrm{M}$, see Subjects and methods section). Surprisingly, pre-treatment with SKF38393 increased the mEPSC amplitudes in slices from cocaine-experienced animals to control levels while mEPSC amplitudes in slices from yoked saline rats were not affected (Figures $1 \mathrm{~b}$ and $\mathrm{c}$ ). The time constant of mEPSC decay was significantly slower in slices from cocaine-experienced animals under basal (ie, in the absence of SKF38393 pre-treatment) conditions (yoke $\tau=5.2 \pm 0.2 \mathrm{~ms}$; cocaine $\left.\tau=6 \pm 0.3 \mathrm{~ms}, t_{(26)}=2.2, p<0.05\right)$, but was increased in the yoked saline group following exposure to SKF38393 (yoke SKF $\tau=6.2 \pm 0.3, t_{(24)}=2.53, p<0.05 \mathrm{vs}$ yoke no SKF; cocaine SKF $\tau=6 \pm 0.3 \mathrm{~ms}$ ) (Figure $1 \mathrm{~b}$ ). The differences in the decay time may reflect the differences in the relative abundance of GluA subunits subtypes (Jonas, 2000; Lu et al, 2009). The basal frequency of mEPSCs in cocaine-experienced animals was $43 \%$ smaller than in yoked saline controls. Following SKF38393 exposure, mEPSC frequency increased to control levels (Figures $1 \mathrm{~d}$ and e). The mean frequency of mEPSCs recorded in the yoked group under the basal conditions was not different from the mean mEPSC frequency measured after SKF38393 preexposure, although 3 out of 12 recorded cells had very frequent events (Figure 1e, inset). mEPSC frequency is traditionally interpreted to reflect the probability of neurotransmitter release. Therefore, our data suggest that the probability of glutamate release is decreased following cocaine selfadministration and that incubation with SKF38393 counteracts this synaptic adaptation. Thus, the deficits in both the amplitude and the frequency of mEPSC are reversed by D1DR stimulation during early abstinence from cocaine self-administration.

We next examined the mEPSCs following longer periods of abstinence. After 3-4 weeks of forced abstinence, the basal mEPSC amplitude in cocaine-experienced animals was approximately $28 \%$ larger than in yoked saline controls (Figures 2a and b). This increase is slightly greater than that reported following 10-14 days of withdrawal from experimenter-administered cocaine in the mouse (Kourrich et al, 2007). As in early abstinence, pre-treatment of slices with SKF38393 eliminated this difference (Figures $2 a$ and b). In contrast to our observations in early abstinence, there were no basal differences in mEPSC decay time (yoke $\tau=6 \pm 0.4 \mathrm{~ms}$; cocaine $\tau=5.7 \pm 0.2 \mathrm{~ms}$; yoke SKF $\tau=6.2 \pm 0.3 \mathrm{~ms}$; cocaine SKF $\tau=5.8 \pm 0.3 \mathrm{~ms}$, Figure 2a) or mEPSC frequency (Figures $2 \mathrm{c}$ and $\mathrm{d}$ ) after this longer period of abstinence. Furthermore, pre-treatment with SKF38393 had no effect on these measures in either the yoked saline or the cocaineexperienced groups.

It can be argued that because exposure to cocaine occurred in animals rather than slices, it is the animals that represent an appropriate $n$ value for the number of statistical samples. We have, therefore, re-analyzed our mEPSCs data by calculating an average of all recorded cells in each animal and then computing the mean of such values for all animals within an experimental group. The results of these analyses for mEPSCs and all other experiments are presented in Table 1. Note that the interpretation of the statistical analyses was the same with both methods of generating the mean values. 

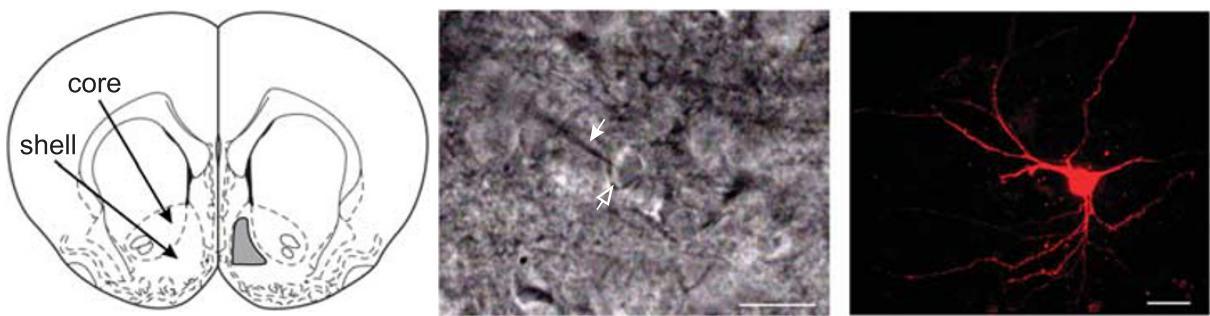

b

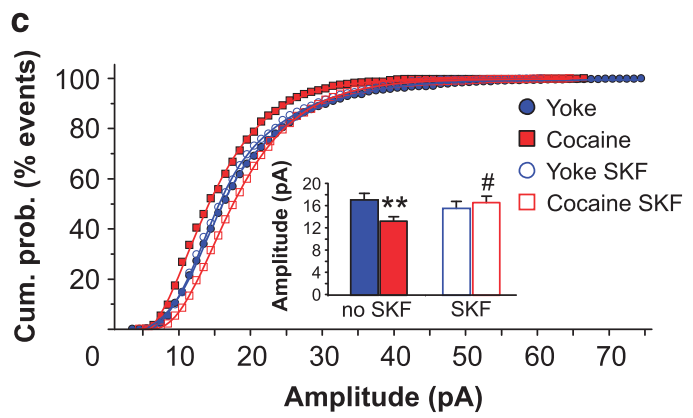

d

e
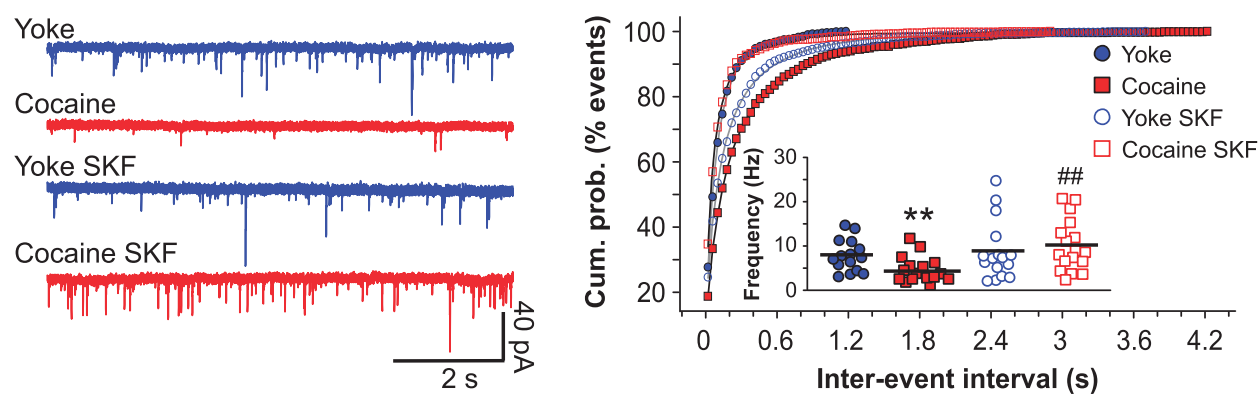

Figure I DIDR stimulation increases the mEPSC amplitude and frequency in cocaine-experienced animals at I-2 days of abstinence. (a) Left, a schematic of a coronal brain section illustrating the two subdivisions of the nucleus accumbens. Shaded box indicates the area of the shell used for all recordings. Middle, an infrared differential interference contrast image of an MSN in the nucleus accumbens shell (open arrow) with the recording electrode (closed arrow) impaling the cell. Right, a confocal microscope image of an accumbens shell MSN filled with Alexa 568. Scale bars, $25 \mu \mathrm{m}$. (b) Left, mEPSC traces from cells in cocaine-experienced and yoked saline animals with and without SKF38393 (I0 $\mu \mathrm{M})$ pre-treatment. Right, same traces normalized to the peak amplitude illustrate differences in mEPSC decay. (c) Cumulative probability distributions indicate reduced mEPSC amplitudes in cells from cocaineexperienced rats relative to yoked saline controls, under basal conditions (ie, without SKF38393 pre-treatment; $p<0.05, \mathrm{~K}-\mathrm{S}$ test). SKF38393 pre-treatment results in a rightward shift of the distribution for cells from the cocaine-experienced, but not yoked saline control group. The inset shows mean mEPSC amplitudes for all groups $\left(n=12-17\right.$ cells/5-6 animals). ${ }^{*} * t_{(28)}=2.98, p<0.01$ vs yoked controls; ${ }^{\#} t_{(32)}=2.66, p<0.05$ vs cocaine no SKF; Student's $t$-test. (d) Representative traces illustrate effects of SKF38393 pre-treatment on mEPSC frequency. (e) Cumulative probability distributions of mEPSC inter-event intervals show reduced frequency of mEPSCs under basal conditions in cocaine-experienced animals relative to yoked saline controls ( $p<0.01, \mathrm{~K}-\mathrm{S}$ test). The mEPSCs frequency deficit is absent following SKF38393 pre-treatment. Inset shows the effect of SKF38393 on mEPSC frequency in all recorded cells (black horizontal lines indicate the mean). Mean ( \pm SEM) frequencies are as follows: yoke $7.8 \pm 0.9 \mathrm{~Hz}$; cocaine $4.4 \pm 0.7 \mathrm{~Hz}$; yoke SKF $8.7 \pm 1.6 \mathrm{~Hz}$; cocaine SKF $10 \pm 1.4 \mathrm{~Hz}$. Notice that three cells from the yoke SKF group had very frequent events contributing to the leftward shift of the cumulative probability distribution. ${ }^{* *} t_{(30)}=2.98, p<0.0$ I vs yoked controls; ${ }^{\# \#} t_{(32)}=3.64, p<0.01$ vs cocaine no SKF; Student's $t$-test.

\section{Pre-Synaptic Effects of Cocaine Self-Administration and D1 Agonist Pre-Treatment}

We attributed the early abstinence decrease in mEPSC frequency to reduced probability of glutamate release. However, the basal decrease in mEPSC amplitude in cocaine-experienced rats may have forced a fraction of small-amplitude synaptic events below the detection limit and contributed to the observed frequency decrease (Stell and Mody, 2002). To confirm the pre-synaptic origin of mEPSC frequency deficits, we examined the PPRs, a measure of synaptic efficacy that is inversely proportional to the pre-synaptic probability of release (Manabe et al, 1993). In early abstinence, the PPR in cells from cocaine-experienced animals was significantly larger than in yoked saline controls across a range of interstimulus intervals (average yoke $\mathrm{PPR}=1.04 \pm 0.05$; average cocaine $P P R=1.24 \pm 0.06)$, consistent with a decrease in the probability of release (Figures $3 \mathrm{a}$ and $\mathrm{c}$ ). This difference was eliminated by pre-treatment with SKF38393 (average yoke $\mathrm{PPR}=1.15 \pm 0.08$; average cocaine $\mathrm{PPR}=1.04 \pm 0.03$; Figures $3 a$ and c). No differences in PPR were observed among any of the groups in late abstinence (average yoke $=1.14 \pm$ 0.07 ; average cocaine $1.1 \pm 0.04$; average yoke $\mathrm{SKF}=1.05 \pm$ 0.06; average cocaine $S K F=1 \pm 0.03$; Figures $3 b$ and d). Collapsing all cells per animal and across each group led to 
a

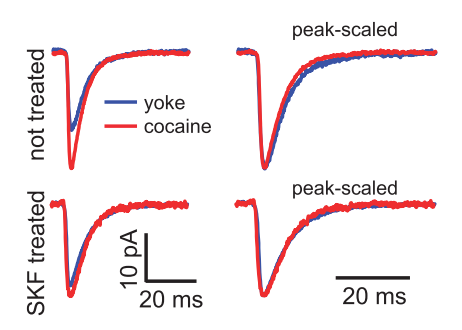

C

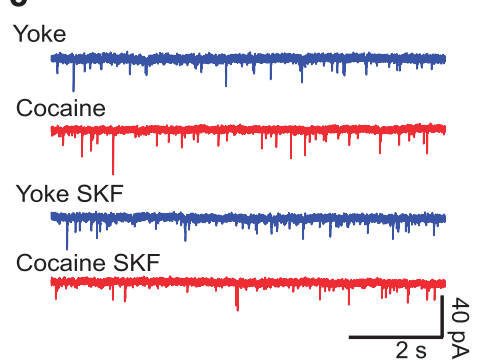

b
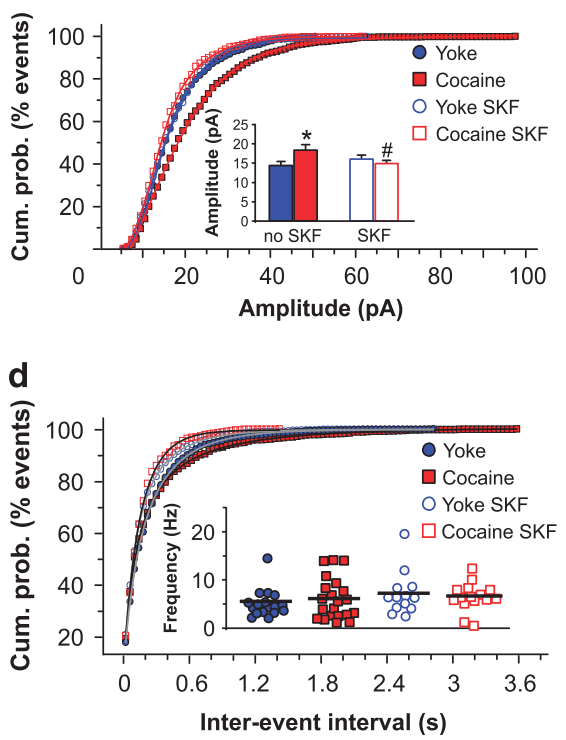

Figure 2 DIDR stimulation decreases the mEPSC amplitude and does not affect frequency in cocaine-experienced animals at 3-4 weeks of abstinence. (a) Left, mEPSC traces from cells in cocaine-experienced and yoked saline animals with and without SKF38393 (I0 $\mu$ M) pre-treatment. Right, same traces normalized to the peak amplitude for comparison of mEPSC decay. (b) Cumulative probability distributions indicate increased basal mEPSC amplitudes in cells from cocaine-experienced rats relative to yoked saline controls $(p<0.0$ I, K-S test). SKF38393 pre-treatment only affects the amplitude distribution in the cocaine-experienced group, shifting it toward smaller mEPSC amplitudes. The inset shows mean mEPSC amplitudes for all groups ( $n=13-20$ cells $/ 5-7$ animals). ${ }^{*} t_{(35)}=2.35, p<0.05$ vs yoked controls; ${ }^{\#} t_{(33)}=2.31, p<0.05$ vs cocaine no SKF; Student's $t$-test. (c) Representative traces illustrate the effects of SKF38393 pre-treatment on mEPSC frequency. (d) Cumulative probability distributions of mEPSC inter-event intervals and scatterplots of mEPSC frequencies (inset). Mean ( \pm SEM) frequencies are as follows: yoke $5 . I \pm 0.7 \mathrm{~Hz}$; cocaine $6.1 \pm 0.9 \mathrm{~Hz}$; yoke SKF $7.2 \pm$ I. $3 \mathrm{~Hz}$; cocaine SKF $6.5 \pm 0.8 \mathrm{~Hz}$. There were no differences between any of the groups in either the cumulative inter-event interval distributions or the mean mEPSC frequencies.

a
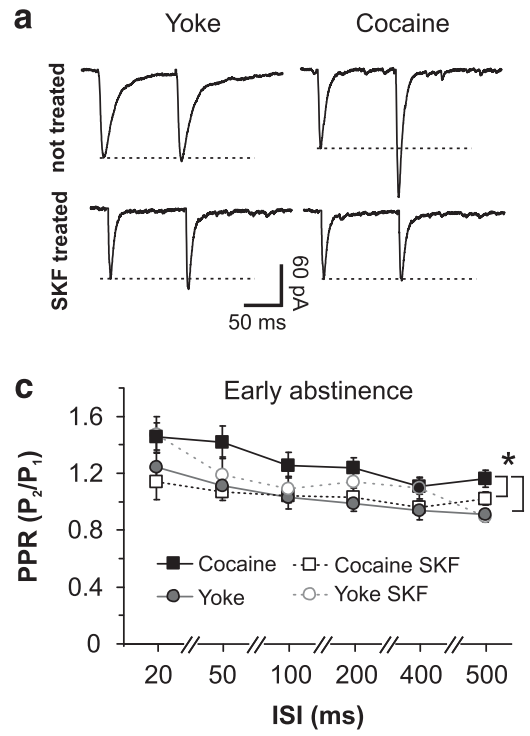
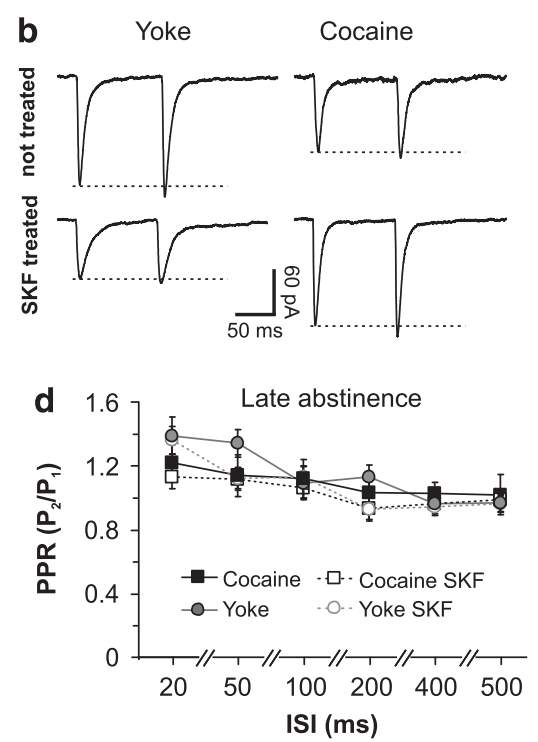

Figure 3 Effects of SKF38393 pre-treatment on PPR in early and late abstinence from cocaine self-administration. (a) Sample paired eEPSC comparing the effects of cocaine exposure and SKF38393 incubation on PPRs in early abstinence from cocaine self-administration. Inter-stimulus interval is I 00 ms. Stimulus artifacts are omitted. (b) Same as in (a) but in late abstinence. (c) Mean PPRs measured at inter-stimulus intervals (ISIs) of 20-500 ms at I-2 days of abstinence from cocaine self-administration. There is a significant main effect of treatment (repeated-measures ANOVA, $\left.F_{(3,44)}=3.353, p=0.027\right)$. Post hocs on the main effect of treatment revealed a significant effect of yoke vs cocaine and cocaine vs cocaine SKF groups (*Tukey's HSD post hoc). In all, II 15 cells from 4 to 5 animals were recorded in each group. (d) Mean paired pulse ratios at 3-4 weeks of abstinence. Differences between groups are not significant (repeated-measures ANOVA, $\left.F_{(3,39)}=1.647, p=0.194\right)$. 10-12 cells from 4 to 5 animals were recorded in each group.

similar conclusions: cocaine experience significantly increased the PPR in early abstinence, an effect that was rescued by pre-treatment with $\operatorname{SKF} 38393\left(\mathrm{~F}_{(3,13)}=4.568\right.$, $p=0.021)$ with significant effects of cocaine $v s$ yoke, cocaine $v s$ cocaine SKF, and cocaine $v s$ yoke SKF groups (Tukey's HSD). There was no effect in late abstinence $\left(\mathrm{F}_{(3,13)}=1.154\right.$, 
$p=0.364)$. Thus, the PPR measurements provide an important confirmation to the mEPSC frequency data both before and after SKF38393 pre-treatment and suggest that D1DR stimulation affects pre-synaptic mechanisms that increase the probability of glutamate release specifically in cocaineexperienced animals in early abstinence from cocaine selfadministration.

\section{Role for CB1 Signaling in Regulation of Glutamate Release}

Cannabinoid receptor system can both regulate glutamate release in the striatum and is sensitive to modulation by D1DRs (Patel et al, 2003; Andre et al, 2010). Activation of CB1 receptors is known to decrease neurotransmitter release (reviewed in Kano et al, 2009). Reduced release probability after cocaine self-administration in early abstinence may therefore suggest stronger basal CB1 receptor activation that could be sensitive to SKF38393 pre-treatment. In this scenario, $\mathrm{CB} 1$ receptor blockade should increase the mEPSC frequency before, but not after the SKF38393 pretreatment. Indeed, we found that in early abstinence, application of a CB1 receptor antagonist, AM251 $(3 \mu \mathrm{M})$ increased the mEPSC frequency by $9.3 \pm 5.3 \%$ of baseline values in cells from yoked saline controls, but led to a $48 \pm 8.9 \%$ increase in cells from cocaine-experienced rats (Figure 4a). After slices had been incubated with SKF38393, this difference was eliminated (Figure 4a). At 3-4 weeks of abstinence from cocaine, AM251 increased the mEPSC frequency to a similar extent in yoke and cocaine slices both before and after incubation with SKF38393 (Figure 4b). These data are consistent with our prediction that D1DR stimulation in cocaine-experienced animals affects $\mathrm{CB} 1$ receptor signaling and that this may contribute to the reduction of glutamate release in early abstinence from cocaine selfadministration.

\section{D1DR Stimulation Restores AMPA/NMDA Ratio to Control Levels in Late Abstinence}

Multiple studies have found that exposure to cocaine modulates the ratio of AMPA to NMDA receptor-mediated currents, an index of the relative excitatory synaptic strength (reviewed in Bowers et al, 2010). We examined the sensitivity of this widely used measure to SKF38393 pre-treatment. At 1-2 days of forced abstinence from cocaine self-administration, the AMPA/NMDA ratio did not differ between yoked saline and cocaine groups (yoke: $4.53 \pm 0.71$; cocaine: $4.69 \pm 0.62$; Figures 5a and b). SKF38393 pre-treatment did not affect the AMPA/NMDA ratio although a trend toward smaller values was observed in slices from cocaine-experienced animals (yoke SKF: $4.37 \pm 0.48$; cocaine SKF: $3.75 \pm 0.38$, $p=0.19$; Figures $5 \mathrm{a}$ and $\mathrm{b}$ ). At 3-4 weeks of abstinence from cocaine self-administration, AMPA/NMDA ratio was $52 \%$ larger in the cocaine-experienced group (yoke: $4.18 \pm 0.49$; cocaine: $6.34 \pm 0.69$; Figures $5 \mathrm{c}$ and d) similar to a previous report (Kourrich et al, 2007). SKF38393 exposure reduced the AMPA/NMDA ratio in cells from cocaine-experienced animals to control levels, but had a negligible effect on cells from yoked saline pairs (yoke SKF: $4.71 \pm 0.7$; cocaine SKF: $4.34 \pm 0.39$; Figures $5 \mathrm{c}$ and $\mathrm{d}$ ). We conclude that AMPA/ NMDA ratio, a broad measure of excitatory synaptic strength, is sensitive to D1DR stimulation in nucleus accumbens shell MSNs of cocaine-experienced, but not yoked saline control animals and that this unique sensitivity develops only after an extended period of abstinence from cocaine selfadministration.

\section{In Vivo Treatment with SKF38393 Mimics the In Vitro Effects}

Our data suggest that D1 receptor stimulation triggers lasting synaptic changes in the slices from cocaine-experienced animals. We sought to investigate whether treatment with SKF38393 in vivo is similarly capable of modulating the strength of excitatory synapses onto the accumbens shell MSNs. To accomplish this, the animals were implanted with guide cannulae targeting the accumbens shell bilaterally. At $24 \mathrm{~h}$ after the last cocaine self-administration session (early abstinence), each animal received a microinfusion of saline into one brain hemisphere and of SKF38393 into the other hemisphere. Following this treatment, the slices were prepared according to the standard protocol and recordings performed within $5 \mathrm{~h}$ of microinjections. We found a robust reduction of both mEPSC frequency and amplitude in cells from saline-treated hemispheres of cocaine-experienced
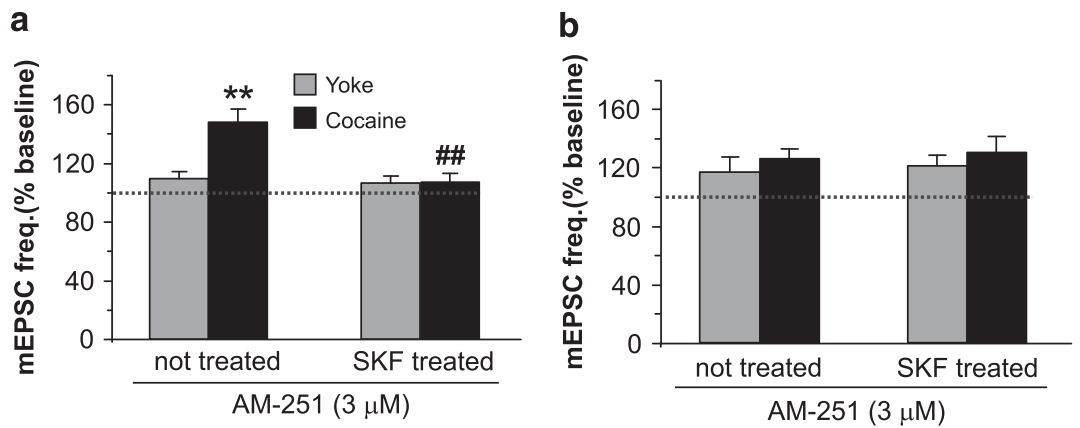

Figure 4 Pre-synaptic effects of cocaine self-administration and DI agonist pre-treatment in early abstinence involve modulation of CBI receptor signaling. (a) Bar histograms illustrate an enhanced effect of AM25I on mEPSC frequency in neurons from cocaine-experienced animals at I-2 days of abstinence from cocaine self-administration. This effect is suppressed following incubation with SKF38393. (b) Same as (a), but at 3-4 weeks of abstinence. In all, 8-II cells from 4 to 5 animals were recorded in each group. ${ }^{*}{ }^{*} t_{(18)}=4.33, p<0.01$ vs not treated yoke; ${ }^{\# \#} t_{(17)}=4.24$, $p<0.01$ vs not treated cocaine; Student's t-tests. 

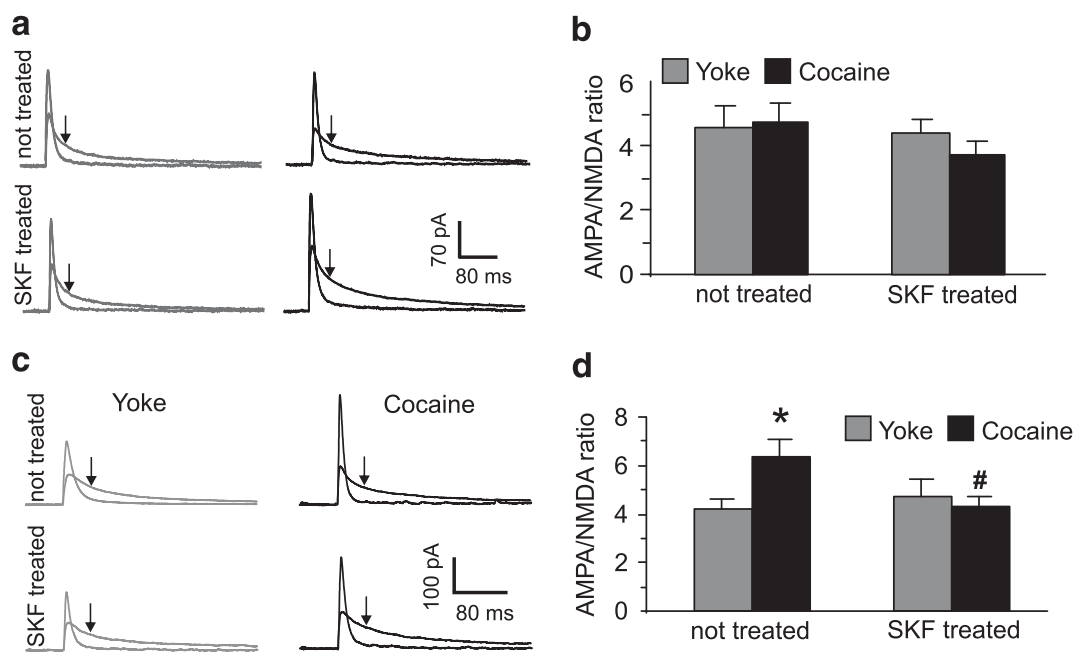

Figure 5 SKF38393 pre-exposure reverses the cocaine-associated changes in AMPA/NMDA ratio. (a, c) Representative average current traces show AMPA (thin traces) and compound, AMPA + NMDA (thick traces) receptor-mediated eEPSCs from yoked saline and cocaine-experienced groups with and without SKF38393 pre-treatment in early (a) and late (c) abstinence. Each trace is an average of 50 individual eEPSCs. For display purposes, AMPA receptormediated currents are shown as outward-going. Arrows indicate time-points for measurement of the NMDA component (see Subjects and methods). (b, $d$ ) Mean AMPA/NMDA ratios in early (b) and late (d) abstinence from cocaine self-administration. In all, I I- 15 cells from 4 to 5 animals were recorded in each of the groups. ${ }^{*} t_{(21)}=2.61, p<0.05$ vs yoke; ${ }^{\#} t_{(24)}=2.71, p<0.05$ vs not treated cocaine; Student's $t$-test.
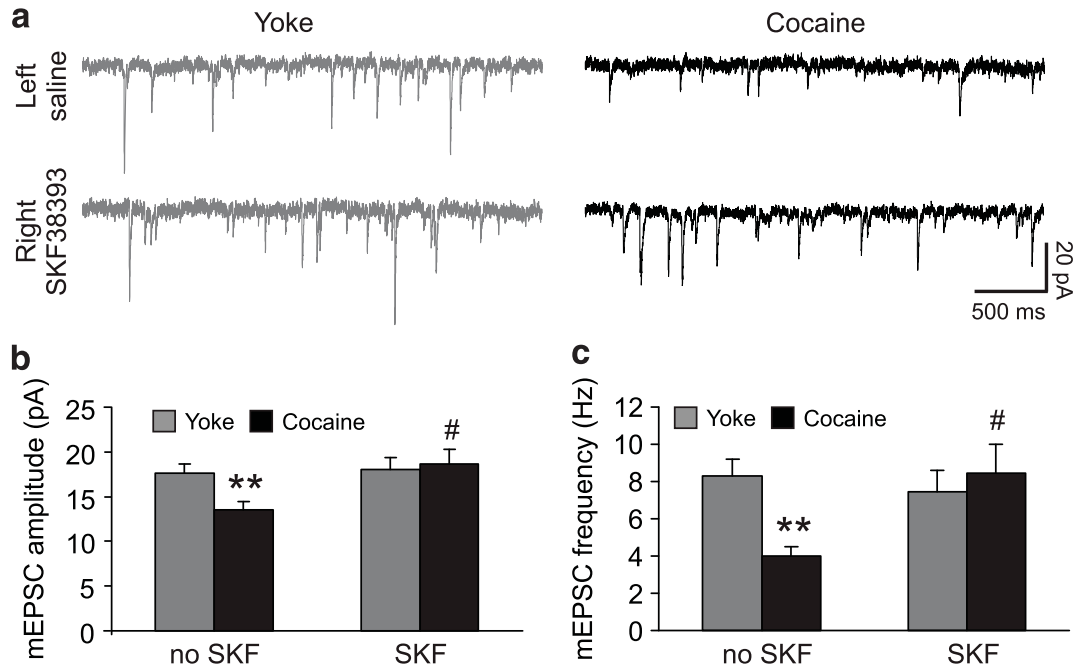

Figure 6 In vivo microinjection of SKF38393 rescues mEPSC amplitude and frequency deficits. (a) Sample mEPSC traces from NAc shell MSNs of yoked saline and cocaine animals following an injection of saline $(0.5 \mu \mid)$ into the NAc shell of the left hemisphere and SKF38393 ( I $\mu \mathrm{g} / 0.5 \mu \mathrm{l})$ into the NAc shell of the right hemisphere. Microinjections and recordings were performed $24 \mathrm{~h}$ following the last self-administration session (see Subjects and methods for details). (b) Decreased mEPSC amplitudes in saline-treated hemispheres are restored to control levels in the SKF38393-treated hemispheres. ** $t_{(19)}=2.9$ I, $p<0.0$ I; ${ }^{t_{(20)}}=2.65, p<0.05$, Student's $t$-tests; C, SKF38393 microinjection rescues the reduction in mEPSC frequency. ${ }^{*} * t_{(19)}=4.31, p<0.00 I^{\prime}$; ${ }^{\#} t_{(20)}=2.67, p<0.05$; Student's $t$-tests; $n=10-1$ I cells from four animals.

animals (Figure 6). In cells from SKF38393-treated hemispheres, both the mEPSC frequency and mEPSCs amplitude deficits were rescued, similar to the rescue observed after in vitro exposure to SKF38393 (Figure 6, compare with Figure 1). The mEPSC decay times, however, were not different between treatment groups (yoke $\tau=4.4 \pm 0.3 \mathrm{~ms}$, cocaine $\tau=4.8 \pm 0.3 \mathrm{~ms}$, yoke SKF $\tau=4.2 \pm 0.2 \mathrm{~ms}$, cocaine SKF $\tau=4.8 \pm 0.2 \mathrm{~ms}$ ). Thus, we confirm a lasting modulation of excitatory synapses by D1DRs in an intact accumbal circuit. Stimulation of D1DRs is known to elicit a variety of cocaine-associated behaviors when administered into the nucleus accumbens (reviewed in Schmidt and Pierce, 2010) and these findings shed light onto possible underlying mechanisms.

\section{DISCUSSION}

In this study, we determined the persistent effects of cocaine self-administration and D1DR activation on the efficacy 
of AMPA receptor-mediated synaptic transmission in the nucleus accumbens shell following brief (1-2 days) and extended (3-4 weeks) abstinence. Our results indicate that incubation with the D1DR agonist, SKF38393, had no appreciable influence on most measures of excitatory synaptic strength in the shell of control rats. In contrast, in cells from cocaine-experienced animals both the early abstinence suppression as well as the late abstinence potentiation of AMPA receptor-mediated signaling were normalized by SKF38393 pre-treatment. Such reversal of cocaine-associated synaptic plasticity occurred in measures implicating pre-synaptic (mEPSC frequency, PPRs) and post-synaptic (mEPSC amplitude, AMPA/NMDA ratio) mechanisms (Table 2). Moreover, the effects of SKF38393 were observed after drug incubation ceased and also after microinjection of this drug in vivo, suggesting recruitment of signaling and effector mechanisms that persist in the absence of pharmacological stimulation. These results describe a range of synaptic adaptations triggered by cocaine self-administration and identify a unique role for D1DRs in gating the maintenance of these neuroadaptations.

\section{D1DR Stimulation Reverses Time-Dependent Post- Synaptic Modifications in Cocaine-Experienced Animals}

During early abstinence, the basal amplitude of mEPSCs was decreased in accumbens shell MSNs from rats that selfadministered cocaine. This effect may indicate a decrease in the expression of post-synaptic AMPA receptors (Conrad et al, 2008; Schumann and Yaka, 2009; Ferrario et al, 2010), which should decrease the AMPA/NMDA ratio. In fact, with non-contingent cocaine administration some studies report decreased AMPA/NMDA ratio in the accumbens shell at a similar abstinence time period (Kourrich et al, 2007; Mameli et al, 2009) although others observe no changes (Kim et al, 2011). Despite a reduction in mEPSC amplitude, we did not observe basal changes in AMPA/NMDA ratio during early abstinence. This may be explained if a decrease in NMDA receptor-mediated currents occurred in parallel with a decrease in AMPA receptor-mediated currents. We observed a small reduction in the basal amplitude of NMDA receptor eEPSCs in cocaine-experienced animals during early abstinence (at normalized stimulus intensity; yoke: $56.3 \pm 9.2 \mathrm{pA}$; cocaine $=45.8 \pm 8.4 \mathrm{pA})$. Nevertheless, it must be noted that the amplitude of AMPA mEPSCs does not reliably predict a change in the AMPA/NMDA ratio because the populations of post-synaptic AMPA receptors activated during miniature and evoked events differ (Thomas et al, 2001; Sara et al, 2011).
In contrast to early abstinence, cocaine self-administration followed by 3-4 weeks of forced abstinence increased basal AMPA mEPSC amplitude and increased the AMPA/ NMDA ratio. These results are consistent with electrophysiological studies following experimenter-administered cocaine (Thomas et al, 2001; Kourrich et al, 2007) and reports of increased surface expression of AMPA receptors following an extended period of abstinence (Boudreau and Wolf, 2005; Boudreau et al, 2007, 2009; Ghasemzadeh et al, 2009; Schumann and Yaka, 2009; Ferrario et al, 2010). The decrease in mEPSC amplitude during early abstinence as well as the increases in mEPSC amplitude and the AMPA/ NMDA ratio in late abstinence were normalized following pre-treatment of slices from cocaine-experienced animals with SKF38393. Thus, cocaine-associated excitatory synaptic plasticity in the accumbens shell can be dynamically regulated by D1DR signaling. Adaptive changes in D1DR expression and signaling observed throughout abstinence (Anderson and Pierce, 2005) are likely to contribute to such dynamic regulation.

\section{Reversal of Pre-Synaptic Deficits by D1DR Stimulation}

During the early abstinence from cocaine self-administration, we observed a decrease in mEPSC frequency accompanied by an increase in the PPR, implicating a presynaptic site of action. These results highlight a difference with the effects of non-contingent cocaine administration that have been reported to increase the mEPSC frequency in two recent reports (Dobi et al, 2011; Kim et al, 2011). Interestingly, Kim et al (2011) found this increase to be specific to D1-expressing MSNs, with a significant decrease in mEPSC frequencies observed in D2-expressing MSNs.

Although D1DRs are predominantly expressed postsynaptically (Levey et al, 1993; Hersch et al, 1995; Yung et al, 1995; Caille et al, 1996), up to a quarter of D1DRs in the nucleus accumbens are pre-synaptic heteroreceptors (Dumartin et al, 2007). Electrophysiological evidence indicates that acute stimulation of D1DRs reduces the frequency of mEPSCs and increases the PPR (Pennartz et al, 1992; Nicola et al, 1996). We found that following SKF38393 pre-exposure, slices from cocaine-experienced animals during early abstinence showed a prominent increase in mEPSC frequency that was accompanied by a decrease in the PPR. These observations suggest that SKF38393 increased the probability of glutamate release in cocaine-experienced animals following brief, but not longer abstinence.

Table 2 Exposure to SKF38393 Reverses Cocaine-Induced Synaptic Adaptations

\begin{tabular}{|c|c|c|c|c|c|c|c|c|c|c|}
\hline & \multicolumn{2}{|c|}{ mEPSC amplitude } & \multicolumn{2}{|c|}{ mEPSC frequency } & \multicolumn{2}{|c|}{ Paired-pulse ratio } & \multicolumn{2}{|c|}{ AMPA/NMDA ratio } & \multicolumn{2}{|c|}{ mEPSC frequency in AM25 I } \\
\hline & Early & Late & Early & Late & Early & Late & Early & Late & Early & Late \\
\hline Cocaine SA & $\downarrow \downarrow$ & $\uparrow$ & $\downarrow \downarrow$ & $\leftrightarrow$ & $\uparrow$ & $\leftrightarrow$ & $\leftrightarrow$ & $\uparrow$ & $\uparrow \uparrow$ & $\leftrightarrow$ \\
\hline Cocaine SA+ SKF38393 & $\uparrow$ & $\downarrow$ & $\uparrow \uparrow$ & $\leftrightarrow$ & $\downarrow$ & $\leftrightarrow$ & $\leftrightarrow$ & $\downarrow$ & $\downarrow \downarrow$ & $\leftrightarrow$ \\
\hline
\end{tabular}

In the cocaine SA row, the arrows indicate significant (one arrow, $p<0.05$; two arrows, $p<0.0$ I) changes relative to saline yokes at the corresponding withdrawal time-point. In the cocaine SA+SKF38393 row, the arrows indicate significant changes relative to the cocaine SA animals at the corresponding time-point. 
A wealth of clinical evidence suggests that interaction between the dopamine and endocannabinoid systems is involved in the pathophysiology of disorders involving the limbic system (Parolaro and Rubino, 2008; Fernández-Ruiz et al, 2010; Kuepper et al, 2010; Pisani et al, 2011). Deletion of CB1 receptors reduces reinforcing properties of cocaine as does administration of CB1 receptor antagonists (Xi et al, 2006; Li et al, 2009; Ramiro-Fuentes et al, 2010). The molecular mechanisms underlying these effects are likely to involve glutamate receptors although the precise details of interaction between the dopamine, glutamate, and cannabinoid signals remain to be worked out. We identify cannabinoid receptor activation as a contributor to the pre-synaptic changes observed in slices from cocaineexperienced animals. Application of the CB1 antagonist, AM251, significantly increased mEPSC frequency in the shell of cocaine-experienced relative to saline control animals in the early abstinence. This difference was abolished following treatment with SKF38393, in line with the reported ability of D1DR agonists to decrease endogenous cannabinoid levels (Patel et al, 2003). Following extended cocaine abstinence, AM251 had similar effects both with and without the SKF38393 incubation, consistent with the lack of differences in $\mathrm{mEPSC}$ frequency and the PPR at this time point.

\section{Summary and Conclusions}

Sensitivity of AMPA receptor-mediated synaptic plasticity to cocaine history including sensitivity to duration of abstinence has been reported by a number of groups (reviewed in Wolf and Ferrario, 2010). Among the most robust findings is the enhancement of AMPA signaling following extended abstinence from non-contingent cocaine. To our knowledge, our results provide the first confirmation that this enhancement persists following extended abstinence from cocaine self-administration and that this enhancement is characterized by post-synaptic neuroadaptations. Notably, in early abstinence from cocaine self-administration we identified a broader pattern of synaptic changes attributable to both pre- and postsynaptic mechanisms.

We found that administration of a D1DR agonist only affected those measures of synaptic efficacy that were altered by cocaine experience (ie, decreased mEPSCs amplitude, frequency, PPR, at 1-2 days and increased mEPSCs amplitudes and AMPA/NMDA ratios at 3-4 weeks of abstinence). It is thus tempting to speculate that synapses modified by cocaine self-administration possess a unique sensitivity to D1DR stimulation. Moreover, D1DRs appear to gate the ability to adjust such modifications. Neuroadaptations associated with cocaine experience may underlie an impaired ability to assign motivational salience to novel rewards unrelated to the drug, similar to impaired learning after saturation of hippocampal synapses by tetanic stimulation (McNaughton et al, 1986; Moser et al, 1998). Normalization of excitatory synaptic efficacy following D1DR stimulation suggests that synapses altered by cocaine self-administration remain plastic and maintain the potential to recover normal function, which has implications for the treatment of cocaine craving and addiction (Haney and Spealman, 2008; Self and Nestler, 1995).

\section{ACKNOWLEDGEMENTS}

This work was supported by NIH Grants R01 DA22339 and K02 DA18678 to RCP.

\section{DISCLOSURE}

The authors declare no conflict of interest.

\section{REFERENCES}

Anderson SM, Famous KR, Sadri-Vakili G, Kumaresan V, Schmidt HD, Bass CE et al (2008). CaMKII: a biochemical bridge linking accumbens dopamine and glutamate systems in cocaine seeking. Nat Neurosci 11: 344-353.

Anderson SM, Pierce RC (2005). Cocaine-induced alterations in dopamine receptor signaling: implications for reinforcement and reinstatement. Pharmacol Ther 106: 389-403.

Andre VM, Cepeda C, Cummings DM, Jocoy EL, Fisher YE, William Yang X et al (2010). Dopamine modulation of excitatory currents in the striatum is dictated by the expression of D1 or D2 receptors and modified by endocannabinoids. Eur J Neurosci 31: 14-28.

Boudreau AC, Ferrario CR, Glucksman MJ, Wolf ME (2009). Signaling pathway adaptations and novel protein kinase A substrates related to behavioral sensitization to cocaine. J Neurochem 110: 363-377.

Boudreau AC, Reimers JM, Milovanovic M, Wolf ME (2007). Cell surface AMPA receptors in the rat nucleus accumbens increase during cocaine withdrawal but internalize after cocaine challenge in association with altered activation of mitogen-activated protein kinases. J Neurosci 27: 10621-10635.

Boudreau AC, Wolf ME (2005). Behavioral sensitization to cocaine is associated with increased AMPA receptor surface expression in the nucleus accumbens. J Neurosci 25: 9144-9151.

Bowers MS, Chen BT, Bonci A (2010). AMPA receptor synaptic plasticity induced by psychostimulants: the past, present, and therapeutic future. Neuron 67: 11-24.

Caille I, Dumartin B, Bloch B (1996). Ultrastructural localization of D1 dopamine receptor immunoreactivity in rat striatonigral neurons and its relation with dopaminergic innervation. Brain Res 730: 17-31.

Chao SZ, Ariano MA, Peterson DA, Wolf ME (2002). D1 dopamine receptor stimulation increases GluR1 surface expression in nucleus accumbens neurons. J Neurochem 83: 704-712.

Conrad KL, Tseng KY, Uejima JL, Reimers JM, Heng L-J, Shaham Y et al (2008). Formation of accumbens GluR2-lacking AMPA receptors mediates incubation of cocaine craving. Nature 454: $118-121$.

Crespo JA, Oliva JM, Ghasemzadeh MB, Kalivas PW, Ambrosio E (2002). Neuroadaptive changes in NMDAR1 gene expression after extinction of cocaine self-administration. Ann NY Acad Sci 965: 78-91.

Dobi A, Seabold GK, Christensen CH, Bock R, Alvarez VA (2011). Cocaine-induced plasticity in the nucleus accumbens is cell specific and develops without prolonged withdrawal. J Neurosci 31: 1895-1904.

Dumartin B, Doudnikoff E, Gonon F, Bloch B (2007). Differences in ultrastructural localization of dopaminergic D1 receptors between dorsal striatum and nucleus accumbens in the rat. Neurosci Lett 419: 273-277.

Fernández-Ruiz J, Hernandez M, Ramos JA (2010). Cannabinoiddopamine interaction in the pathophysiology and treatment of CNS disorders. CNS Neurosci Ther 16: e72-e91.

Ferrario CR, Li X, Wang X, Reimers JM, Uejima JL, Wolf ME (2010). The role of glutamate receptor redistribution in locomotor sensitization to cocaine. Neuropsychopharmacology 35: 818-833. 
Ferrario CR, Loweth JA, Milovanovic M, Ford KA, Galinanes GL, Heng LJ et al (2011). Alterations in AMPA receptor subunits and TARPs in the rat nucleus accumbens related to the formation of $\mathrm{Ca}(2+)$-permeable AMPA receptors during the incubation of cocaine craving. Neuropharmacology 61: 1141-1151.

Ghasemzadeh MB, Mueller C, Vasudevan P (2009). Behavioral sensitization to cocaine is associated with increased glutamate receptor trafficking to the postsynaptic density after extended withdrawal period. Neuroscience 159: 414-426.

Haney M, Spealman R (2008). Controversies in translational research: drug self-administration. Psychopharmacology (Berl) 199: 403-419.

Harvey J, Lacey MG (1996). Endogenous and exogenous dopamine depress EPSCs in rat nucleus accumbens in vitro via D1 receptors activation. J Physiol 492(Pt 1): 143-154.

Hersch SM, Ciliax BJ, Gutekunst CA, Rees HD, Heilman CJ, Yung $\mathrm{KK}$ et al (1995). Electron microscopic analysis of D1 and D2 dopamine receptor proteins in the dorsal striatum and their synaptic relationships with motor corticostriatal afferents. J Neurosci 15: 5222-5237.

Hevers W, Lüddens H (2002). Pharmacological heterogeneity of gamma-aminobutyric acid receptors during development suggests distinct classes of rat cerebellar granule cells in situ. Neuropharmacology 42: 34-47.

Johansen PA, Hu XT, White FJ (1991). Relationship between D1 dopamine receptors, adenylate cyclase, and the electrophysiological responses of rat nucleus accumbens neurons. J Neural Transm Gen Sect 86: 97-113.

Jonas P (2000). The time course of signaling at central glutamatergic synapses. News Physiol Sci 15: 83-89.

Kalivas PW, McFarland K (2003). Brain circuitry and the reinstatement of cocaine-seeking behavior. Psychopharmacology 168: 44-56.

Kalivas PW, O'Brien C (2008). Drug addiction as a pathology of staged neuroplasticity. Neuropsychopharmacology 33: 166-180.

Kano M, Ohno-Shosaku T, Hashimotodani Y, Uchigashima M, Watanabe M (2009). Endocannabinoid-mediated control of synaptic transmission. Physiol Rev 89: 309-380.

Kim J, Park BH, Lee JH, Park SK, Kim JH (2011). Cell type-specific alterations in the nucleus accumbens by repeated exposures to cocaine. Biol Psychiatry 69: 1026-1034.

Kourrich S, Rothwell PE, Klug JR, Thomas MJ (2007). Cocaine experience controls bidirectional synaptic plasticity in the nucleus accumbens. J Neurosci 27: 7921-7928.

Kourrich S, Thomas MJ (2009). Similar neurons, opposite adaptations: psychostimulant experience differentially alters firing properties in accumbens core versus shell. J Neurosci 29: 12275-12283.

Kuepper R, Morrison PD, van Os J, Murray RM, Kenis G, Henquet C (2010). Does dopamine mediate the psychosis-inducing effects of cannabis? A review and integration of findings across disciplines. Schizophr Res 121: 107-117.

Levey AI, Hersch SM, Rye DB, Sunahara RK, Niznik HB, Kitt CA et al (1993). Localization of D1 and D2 dopamine receptors in brain with subtype-specific antibodies. Proc Natl Acad Sci USA 90: 8861-8865.

Li X, Hoffman AF, Peng XQ, Lupica CR, Gardner EL, Xi ZX (2009). Attenuation of basal and cocaine-enhanced locomotion and nucleus accumbens dopamine in cannabinoid CB1-receptorknockout mice. Psychopharmacology (Berl) 204: 1-11.

Lu W, Shi Y, Jackson AC, Bjorgan K, During MJ, Sprengel R et al (2009). Subunit composition of synaptic AMPA receptors revealed by a single-cell genetic approach. Neuron 62: 254-268.

Mameli M, Halbout B, Creton C, Engblom D, Parkitna JR, Spanagel $\mathrm{R}$ et al (2009). Cocaine-evoked synaptic plasticity: persistence in the VTA triggers adaptations in the NAc. Nat Neurosci 12: 1036-1041.

Manabe T, Wyllie DJ, Perkel DJ, Nicoll RA (1993). Modulation of synaptic transmission and long-term potentiation: effects on paired pulse facilitation and EPSC variance in the CA1 region of the hippocampus. J Neurophysiol 70: 1451-1459.

Mangiavacchi S, Wolf ME (2004). D1 dopamine receptor stimulation increases the rate of AMPA receptor insertion onto the surface of cultured nucleus accumbens neurons through a pathway dependent on protein kinase A. J Neurochem 88: 1261-1271.

McCutcheon JE, Wang X, Tseng KY, Wolf ME, Marinelli M (2011). Calcium-permeable AMPA receptors are present in nucleus accumbens synapses after prolonged withdrawal from cocaine self-administration but not experimenter-administered cocaine. J Neurosci 31: 5737-5743.

Mcnaughton BL, Barnes CA, Rao G, Baldwin J, Rasmussen M (1986). Long-term enhancement of hippocampal synaptic transmission and the acquisition of spatial information. J Neurosci 6: 563-571.

Moser EI, Krobert KA, Moser MB, Morris RG (1998). Impaired spatial learning after saturation of long-term potentiation. Science 281: 2038-2042.

$\mathrm{Mu}$ P, Moyer JT, Ishikawa M, Zhang Y, Panksepp J, Sorg BA et al (2010). Exposure to cocaine dynamically regulates the intrinsic membrane excitability of nucleus accumbens neurons. J Neurosci 30: 3689-3699.

Murase K, Ryu PD, Randic M (1989). Excitatory and inhibitory amino acids and peptide-induced responses in acutely isolated rat spinal dorsal horn neurons. Neurosci Lett 103: 56-63.

Nicola SM, Kombian SB, Malenka RC (1996). Psychostimulants depress excitatory synaptic transmission in the nucleus accumbens via presynaptic D1-like dopamine receptors. J Neurosci 16: 1591-1604.

Parolaro D, Rubino T (2008). The role of the endogenous cannabinoid system in drug addiction. Drug News Perspect 21: 149-157.

Patel S, Rademacher DJ, Hillard CJ (2003). Differential regulation of the endocannabinoids anandamide and 2-arachidonylglycerol within the limbic forebrain by dopamine receptor activity. J Pharmacol Exp Ther 306: 880-888.

Pennartz CM, Dolleman-Van der Weel MJ, Kitai ST, Lopes da Silva FH (1992). Presynaptic dopamine D1 receptors attenuate excitatory and inhibitory limbic inputs to the shell region of the rat nucleus accumbens studied in vitro. J Neurophysiol 67: 1325-1334.

Pierce RC, Kumaresan V (2006). The mesolimbic dopamine system: the final common pathway for the reinforcing effect of drugs of abuse? Neurosci Biobehav Rev 30: 215-238.

Pisani V, Madeo G, Tassone A, Sciamanna G, Maccarrone M, Stanzione $\mathrm{P}$ et al (2011). Homeostatic changes of the endocannabinoid system in Parkinson's disease. Mov Disord 26: 216-222.

Ramiro-Fuentes S, Ortiz O, Moratalla R, Fernandez-Espejo E (2010). Intra-accumbens rimonabant is rewarding but induces aversion to cocaine in cocaine-treated rats, as does in vivo accumbal cannabinoid CB1 receptor silencing: critical role for glutamate receptors. Neuroscience 167: 205-215.

Ryman-Rasmussen JP, Nichols DE, Mailman RB (2005). Differential activation of adenylate cyclase and receptor internalization by novel dopamine D1 receptor agonists. Mol Pharmacol 68: 1039-1048.

Sara Y, Bal M, Adachi M, Monteggia LM, Kavalali ET (2011). Usedependent AMPA receptor block reveals segregation of spontaneous and evoked glutamatergic neurotransmission. J Neurosci 31: 5378-5382.

Schilström B, Yaka R, Argilli E, Suvarna N, Schumann J, Chen BT et al (2006). Cocaine enhances NMDA receptor-mediated currents in ventral tegmental area cells via dopamine D5 receptor-dependent redistribution of NMDA receptors. $J \mathrm{Neu}$ rosci 26: 8549-8558.

Schmidt HD, Anderson SM, Pierce RC (2006). Stimulation of D1-like or D2 dopamine receptors in the shell, but not the core, 
of the nucleus accumbens reinstates cocaine-seeking behaviour in the rat. Eur J Neurosci 23: 219-228.

Schmidt HD, Pierce RC (2010). Cocaine-induced neuroadaptations in glutamate transmission. Ann NY Acad Sci 1187: 35-75.

Schramm-Sapyta NL, Olsen CM, Winder DG (2006). Cocaine self-administration reduces excitatory responses in the mouse nucleus accumbens shell. Neuropsychopharmacology 31: 1444-1451.

Schumann J, Yaka R (2009). Prolonged withdrawal from repeated noncontingent cocaine exposure increases NMDA receptor expression and ERK activity in the nucleus accumbens. J Neurosci 29: 6955-6963.

Self DW, Nestler EJ (1995). Molecular mechanisms of drug reinforcement and addiction. Annu Rev Neurosci 18: 463-495.

Stell BM, Mody I (2002). Receptors with different affinities mediate phasic and tonic GABA(A) conductances in hippocampal neurons. J Neurosci 22: RC223.
Thomas MJ, Beurrier C, Bonci A, Malenka RC (2001). Long-term depression in the nucleus accumbens: a neural correlate of behavioral sensitization to cocaine. Nat Neurosci 4: 1217-1223.

Wolf ME (2010). The Bermuda Triangle of cocaine-induced neuroadaptations. Trends Neurosci 33: 391-398.

Wolf ME, Ferrario CR (2010). AMPA receptor plasticity in the nucleus accumbens after repeated exposure to cocaine. Neurosci Biobeh Rev 35: 185-211.

Xi ZX, Gilbert JG, Peng XQ, Pak AC, Li X, Gardner EL (2006). Cannabinoid CB1 receptor antagonist AM251 inhibits cocaineprimed relapse in rats: role of glutamate in the nucleus accumbens. J Neurosci 26: 8531-8536.

Yung KK, Bolam JP, Smith AD, Hersch SM, Ciliax BJ, Levey AI (1995). Immunocytochemical localization of D1 and D2 dopamine receptors in the basal ganglia of the rat: light and electron microscopy. Neuroscience 65: 709-730. 